\title{
Ontogenetik Varyabilitenin ve Bitki Yoğunluğunun Şeker Otu Verimine Etkisi
}

\author{
L. Sezen TANSI ${ }^{1} \quad$ Elnaz SAMADPOURRIGANI ${ }^{1} \quad$ Selin GEDİK $^{1} \quad$ Amir SOLTANBEIGI $^{2}$ \\ ${ }^{1}$ Çukurova University, Faculty of Agriculture, Department of Crop Fields, Balcal1- Adana \\ ${ }^{2}$ Afyon Kocatepe University, Ahmet Necdet Sezer Campus, Food Control Research and Application Center, \\ Afyonkarahisar. \\ $\triangle$ : sgedik@cu.edu.tr
}

Geliş (Received): 04.11.2017

Kabul (Accepted): 15.12.2017

\begin{abstract}
ÖZET: Şeker otu (Stevia rebaudiana Bertoni) Compositea familyasına ait çok yıllık bir kısa gün bitkisidir. Ülkemizde doğal olarak bulunmamakla birlikte Paraguay ve Brezilya orijinli tropik ve subtropik bir bitkidir. Kalorisiz bir tatlandırıcı olması nedeniyle, diyetlerde ve tıpta şeker hastalarının tatlandırıcılarında kullanılmaktadır. Sakkarozdan 300-350 kat daha fazla tatlandırıcı olması nedeniyle gıda sanayinde içki, meşrubat, tatlı, bisküvi ve çikolatalarda kullanımı tercih edilmektedir. 2013 yılında çok küçük ve çimlenme oranı düşük tohumlardan kontrollü koşullarda elde edilen fideler tarlaya şaşırtılmış olup gerekli bakım işlemleri yapılmıştır. İlk yıl bitkiler, kök geliştirmiş ve elde edilen veriler burada değerlendirilmemiştir. Çalışmada, Şeker otu bitkilerinde, sonbahardaki kısa günlerde, ontogenetik varyabilite ve farklı bitki yoğunluğunun bitki boyu, dal sayısı,taze ve kuru herba, taze ve kuru yaprak, taze ve kuru çiçek yerimlerine olan etkileri incelenerek Çukurova Koşullarındaki performansları saptanmıştır. Elde edilen veriler MSTAT-C paket programında Tesadüf Bloklarında Faktöriyel Deneme Deseni'ne göre değerlendirilmiştir. En yüksek kuru yaprak verimi, çiçeklenme öncesi denemenin 2. yılında (300 kg/da) ve 30x60 cm bitki yoğunluğunda elde edilmiştir. Şeker otu Çukurova koşullarında iyi bir performans göstermiştir. Bu çalışma, şeker otu bitkisinin bölgemiz koşullarında ilk kez kültüre alınması yönünden önem arz etmektedir.

Anahtar Kelimeler: Stevia rebaudiana, bitki sıklığı, ontogenetik varyabilite.
\end{abstract}

\section{Effects of Ontogenetic variability and Plant Density on Yield of Stevia}

\begin{abstract}
Stevia (Stevia rebaudiana Bertoni),belonging to the Compositea family, is a short-day perennial herb. It is native to tropic and subtropic areas of Paraguay and Brasil, so, it is not found as wild in Turkey. Because of nocalorie source of sweetness it is commonly used is in diet solutionsas a natural sweetener plant.Also it is preferably used in food sector soft drinks, sweets, biscuits and chocolates due tothe 300-350 times sweeter than sucrose. For the field trials in 2013 tiny seeds with low germination rate were grown in viols, then the obtained seedlings were transplanted into field and necessary cultivation procedures were followed. The data from the one year old plants, due to root development were not evaluated. In order to determine the performance of the Stevia under Çukurova conditions effects of ontogenetic variability and various plant populations on plant components such as plant height, number of branches, green and dry leaf and flower yield were investigated during the short days of fall season. The data were analyzed according to the factorial design in randomized complete block design using with MSTAT statistical software. The highest dried leaf yield (300 kg da-1) was obtained from two-year-old plants spaced 30x60 $\mathrm{cm}$ at pre-flowering stage and second year of field experiments in autumn 2014. The performance of Stevia is promising under Çukurova conditions. This study is of great importance for Çukurova due to first cultivation research of Stevia

Keywords: Stevia rebaudiana, planting space, ontogenetic variability.
\end{abstract}

\section{GíRIŞ}

Stevia rebaudiana Asteraceae familyasından çok yıllık subtropik bir bitki olup, kısa ve sıcak günlerde çiçek açmaktadır (Brandle ve ark.,1998; Geuns, 2003; Ceunen,2012). Dünya pazarlarındaki talebi, içerdiği steviol glikozitleri nedeniyle, düşük kalorili doğal bir tatlandırıcı olmasından kaynaklanmaktadır (Serfaty ve ark.,2013). 2005 yılında, Çin dünyanın en büyük Stevia üreticisi (\% 75) olmuş ve üretim kapasitesi 2007 y1lında, 5000 tondan, 2009 y1linda 11789 tona kadar yükselmiştir (Global Market, 2011). 2010 yılı ekim ay1 istatistiklerine göre de, 35 ülke Stevia üreticilerine katılmıştır. 2012 y1lı istatistiklerine göre Stevia \% 40 şeker, \% 57.2 aspartam, \% 52.4 sakkaroz ve \% 9.6 oranlarında başka tatlandırıcılar ile yer değişeceği ileri sürülmektedir (Rajagopal, 2010). Stevia, 2004 yılından itibaren Tarım ve Köyişleri Bakanlığının pozitif bitkiler listesinde yer almaktadır (Tarım ve Köyişleri Bakanlığı, 2010). 2010 yılında Stevia bitkisinden elde edilen özün ithalat miktarı $408 \mathrm{~kg}$ ve $8775 €, 2011$ y1lında $25 \mathrm{~kg}, 1290 €$ ve 2012 y1lnda $5 \mathrm{~kg}$ ile $258 €$, ihracat miktarı ise ilaç sanayiinde kullanılanlar hariç $4 \mathrm{~kg}$ ve $15935 €$ 'dur (TÜİK, 2014). 12 saat gün uzunluğunda çiçeklenme \% 100 olmaktadır (Kafle, 2011). Çiçeklenme Steviol glikozitlerinin miktarını etkileyen en önemli etken olup, optimal yaprak hasat zamanı, steviol glikozitlerinin en yüksek noktaya ulaştığı çiçeklenme başlangıcıdır (Kang ve Lee,1981). Stevia'da ontogenetik varyabilite kaliteyi etkilemekte olup en yüksek steviol glikozitleri çiçek tomurcuk oluşumundan itibaren \% 10 dan daha az çiçeklenmenin olduğu döneme kadar elde edilmektedir. Çiçekler açtıkça yapraklardaki steviol oranlarıda düşmektedir (Ceunen ve ark.,2012). Steviol 
glikozitlerinin birikimi kuru yaprak ağırlığı ile pozitif ilişkilidir (Metivierve Viana,1979). Hem yaprak verimi hem de steviol glikozitleri için çiçeklenme başlangıcı çevre koşullarına göre değiştiği için hasat zamanlarının belirlenmesinde çevre koşullarının büyük etkisi olmaktadır (Pereira ve ark., 2016). Stevia'da verim ve kaliteyi etkileyen diğer önemli agronomik karakterlerden biriside bitki yoğunluğudur (Talei ve ark.,2012). Bu nedenle çalışmamızda, Çukurova koşullarında ontogenetik varyabilite ve farklı ekim sıklıklarının Stevia rebaudiana'nın verimi üzerine etkileri incelenmiştir.

\section{MATERYAL ve YÖNTEM}

Paraguay'dan temin edilen Stevia rebaudiana'nın tohumları çok küçük ve çimlenme gücü az olduğu için, $24{ }^{\circ} \mathrm{C}$ 'de tohumlar Çukurova Üniversitesi, Biyoteknoloji Merkezinde önceden hazırlanmış plastik kutulara (1:1:1 oranında elenmiş ahır gübresi, toprak ve kumdan oluşan) ekilmiş, elde edilen fideler seraya taşınmışlar ve 1 ay süreyle serada muhafaza edilen fideler sonrasında, 29 Nisan 2013 tarihinde Çukurova Üniversitesi, Ziraat Fakültesi, Tarla Bitkileri Bölümü deneme alanına 3 tekrarlamalı olarak $30 \times 60,45 \times 60$ ve $60 \times 60 \mathrm{~cm}$ ekim sıklıklarında şaşırtılmışlardır.

İlk yıl bitkiler yeni şaşırtıldıkları için toprağa tutunma aşamasında yeterli büyümeyi gösteremediklerinden dolayı değerlendirilmemiştir. İlkbaharda yeniden toprak üstüne çıkan bitkilerde gerekli bakım işleri ve gözlemler yapıldıktan sonra 2 . y1lda biçimler gerçekleştirilmiştir. Her parsel 7 sıradan oluşmuştur. Kenar tesirler çıkarıldıktan sonra 2 sıra çiçeklenme öncesi, diğer 2 sırada çiçeklenme sırası olarak 10.8.2014 ve 20.9.2014 tarihlerinde sonbaharda hasat edilmiş ve incelenen özelliklerdenelde edilen veriler MSTAT-C paket programinda Tesadüf Bloklarında Faktöriyel Deneme Desenine göre değerlendirilmiştir.

\section{BULGULAR ve TARTIŞMA}

Bitki boyu değerleri arasında hasat zamanlarına göre önemli farklılıklar saptanmamış olup, bitki yoğunluğuna göre bitki boyları önemli derecede değişmiştir. En yüksek bitki boyu değeri $(60.33 \mathrm{~cm}), 30 \times 60 \mathrm{~cm}$ sıklığındaki çalışmamızdaki en yüksek bitki yoğunluğundan elde edilmiştir (Çizelge 1). Bulgularımız, bitki boyu ve yaprak verimlerinin ekim sıklıklarına göre değiştiğini ve $50 \times 20 \mathrm{~cm}$ ekim sıklığında bitki yoğunluğu artıkça yüksek verimlerin elde edildiğini bildiren Taleive ark., (2012.) ile uyum içerisindedir.

Stevia rebaudiana' da kendine uyuşmazlık olduğu için tohumla üretimde steviol seviyelerinde büyük varyasyonlar görülmektedir Bundan dolayı homojen bitkileri üretmek için çelikle, veya yaprak eksplantı ile üretim önerilmektedir (Tamura ve ark.,1984). Çalışmamızda tohumdan yetiştirilen bitkiler arasında morfolojik yönden farklılıklar saptanmış olup, bu durum sonuçlara da yansımıştır. Ancak bu araştırmaile, şeker otunun bölgemiz koşullarında sonbahar dönemi çiçeklenme öncesi ve sırası verimpotansiyellerinin belirlenmesi açısından önemli sonuçlar elde edilmiştir. Dal sayısı değerleri hasat zamanları ve bitki yoğunluklarına göre önemli derecede değişmiştir. En yüksek dal sayısı değerleri, bitki yoğunluklarına göre 30x60 cm siklıkta (28.20adet bitki ${ }^{-1}$ ) ve hasat zamanlarına göre çiçeklenme sırasında (26.67 adet bitki 1) elde edilmiştir (Çizelge 1). Taze herba verimi, kuru herba verimi, taze yaprak ve kuru yaprak verimleri yönünden bitki yoğunluklarına ve hasat zamanlarına göre önemli farklılıklar saptanırken, kuru herba, taze ve kuru yaprak verimlerinde interaksiyonlarda istatistiksel olarak önemli bulunmuştur (Çizelge2,3). En yüksek taze herba, kuru herba, taze yaprak ve kuru yaprak değerleri en yüksek bitki yoğunluğunda $(30 x 60 \mathrm{~cm}$ sıklıkta) ve ontogenetik varyabiliteye göre farklı hasat zamanları içerisinde çiçeklenme öncesinde elde edilmiştir. Benzer şekilde Madan ve ark., (2010) bitki yoğunluğunun 83000 bitki/ha'dan 111000 bitki/ha'a kadar arttıkça yaprak verimlerinin de arttığını bildirmişlerdir.Kumar ve ark., (2013) ise, biokütle birikiminin $30 \times 30 \mathrm{~cm}$ sıklığında \% 41.2 oranında gerçekleşirken $60 \times 45 \mathrm{~cm}$ sıklıkta bu oranın \% 42.8' e yükseldiğini belirtmişlerdir.

Kuru herba (425.00 kg da $\left.{ }^{-1}\right)$, taze $\left(1182.58 \mathrm{~kg} \mathrm{da}^{-1}\right)$ ve kuru yaprak verimleri (300.11 $\left.\mathrm{kg} \mathrm{da}^{-1}\right)$ yönünden interaksiyonlar önemli bulunmuş ve yine en yüksek değerler çiçeklenme öncesi ve 30x60 cm sıklıktaki bitki yoğunluklarında elde edilmiştir (Çizelge 2, 3). Uzun günler taze herba ağırlığını artırmaktadır (Serfaty ve ark., 2013). Kisa günler ise çiçeklenmesini sağlamaktadır (Lima Filho ve ark., 2004; Ceunen ve ark., 2012). Kış koşulları ile karşılaştırıldığında yaz verimlerinde dikkati çekecek şekilde artışlar olmaktadır (Allam ve ark.,2001).

Çizelge 1.Çukurova koşullarında ontogenetik varyabilite ve bitki yoğunluğunun şeker otunun bitki boyu ve dal sayısı değerlerine etkileri

\begin{tabular}{|c|c|c|c|c|c|c|c|c|}
\hline \multirow{3}{*}{ Hasat Zamanları } & \multicolumn{4}{|c|}{ BİTKİ BOYU (cm) } & \multirow{2}{*}{\multicolumn{4}{|c|}{$\frac{\text { DAL SAYISI (adet bitki }{ }^{-1} \text { ) }}{\text { Bitki yoğunluğu }}$}} \\
\hline & \multicolumn{3}{|c|}{ Bitki yoğunluğu } & \multirow[b]{2}{*}{ Ortalama } & & & & \\
\hline & $30 \times 60$ & $45 \times 60$ & $60 \times 60$ & & $30 \times 60$ & $45 \times 60$ & $60 \times 60$ & Ortalama \\
\hline $\begin{array}{l}\text { Çiçeklenme } \\
\text { öncesi }\end{array}$ & 62.65 & 52.52 & 50.43 & 55.20 & 24.82 & 18.29 & 11.15 & $18.09 \mathrm{~b}$ \\
\hline Çiçeklenme sırası & 58.00 & 52.71 & 56.50 & 55.74 & 31.58 & 26.33 & 22.12 & $26.67 \mathrm{a}$ \\
\hline Ortalama & $60.33 \mathrm{a}$ & $52.62 \mathrm{~b}$ & $53.47 \mathrm{~b}$ & & $28.20 \mathrm{a}$ & $22.31 \mathrm{~b}$ & 16.63 & \\
\hline EGF $(\% 5)$ & \multicolumn{4}{|c|}{$\mathrm{EGF}_{\mathrm{by}}: 5.15 \mathrm{EGF}_{\mathrm{int}}: \mathrm{ÖD} \mathrm{EGF}_{\mathrm{hz}}: \mathrm{ÖD}$} & \multicolumn{4}{|c|}{$\mathrm{EGF}_{\text {by: }}: 2.39 \quad \mathrm{EGF}_{\text {int }}: \mathrm{O} D \mathrm{EGF}_{\mathrm{hz}}: 1.95$} \\
\hline
\end{tabular}


Çizelge 2.Çukurova koşullarında ontogenetik varyabilite ve bitki yoğunluğunun şeker otunun taze herba ve kuru herba verimlerine etkileri

\begin{tabular}{|c|c|c|c|c|c|c|c|c|}
\hline \multirow{3}{*}{$\begin{array}{c}\text { Hasat } \\
\text { Zamanları }\end{array}$} & \multicolumn{4}{|c|}{ TAZE HERBA VERİMİ $\left(\mathrm{kg} \mathrm{da}^{-1}\right)$} & \multicolumn{4}{|c|}{ KURU HERBA VERİMİ (kg da $\left.{ }^{-1}\right)$} \\
\hline & \multicolumn{3}{|c|}{ Bitki yoğunluğu } & \multirow[b]{2}{*}{ Ortalama } & \multicolumn{3}{|c|}{ Bitki yoğunluğu } & \multirow[b]{2}{*}{ Ortalama } \\
\hline & $30 \times 60$ & $45 \times 60$ & $60 \times 60$ & & $30 \times 60$ & $45 \times 60$ & $60 \times 60$ & \\
\hline $\begin{array}{l}\text { Çiçeklenme } \\
\text { öncesi } \\
\text { Çiçeklenme } \\
\text { sırası }\end{array}$ & 1173.32 & $\begin{array}{l}838.24 \\
563.21\end{array}$ & $\begin{array}{l}528.56 \\
514.71\end{array}$ & $1028.45 \mathrm{a}$ & $263.46 \mathrm{~b}$ & $\begin{array}{l}220.79 \mathrm{bc} \\
136.99 \mathrm{~cd}\end{array}$ & $\begin{array}{l}125.32 \mathrm{~d} \\
116.44 \mathrm{~d}\end{array}$ & $\begin{array}{l}257.04 \mathrm{a} \\
172.30 \mathrm{~b}\end{array}$ \\
\hline Ortalama & $1445.94 \mathrm{a}$ & $700.73 \mathrm{~b}$ & $521.64 \mathrm{~b}$ & & $344.23 \mathrm{a}$ & $178.89 \mathrm{~b}$ & $120.88 \mathrm{~b}$ & \\
\hline $\mathrm{EGF}(\% 5)$ & \multicolumn{4}{|c|}{$\mathrm{EGF}_{\mathrm{by}}: 272.2 \mathrm{EGF}_{\mathrm{int}}: \mathrm{ÖD} \mathrm{EGF}_{\mathrm{hz}}: 222.2$} & \multicolumn{4}{|c|}{$\mathrm{EGF}_{\mathrm{by}}: 55.59 \mathrm{EGF}_{\mathrm{int}}: 84.28 \mathrm{EGF}_{\mathrm{hz}}: 48.66$} \\
\hline
\end{tabular}

Çizelge 3.Çukurova koşullarında ontogenetik varyabilite ve bitki yoğunluğunun şeker otunun taze yaprak ve kuru yaprak verimlerine etkileri

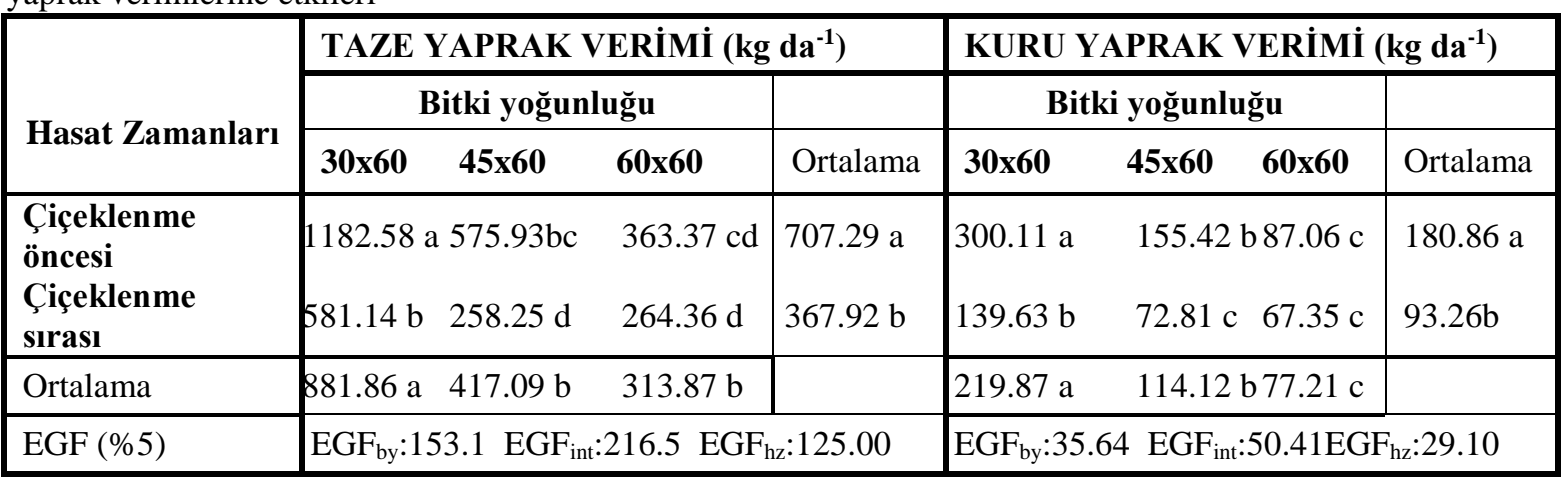

Taze $\left(93.10 \mathrm{~kg} \mathrm{da}^{-1}\right)$ ve kuru çiçek verimleri de (29.94 $\left.\mathrm{kg} \mathrm{da}^{-1}\right)$ herba ve yaprak verimlerine benzer şekilde 30x60 cm sıklıktaki bitki yoğunluğunda elde edilmiştir (Çizelge 4). Şeker otu bitkisinin ticari olarak değerlendirilen kısımları yapraklar olduğu için çiçek verimlerine ilişkin literatür bilgilerine rastlanmamıştır. Bölgemiz koşullarında çiçeklenme kış öncesi Çizelge 4. Çukurova koşullarında bitki yoğunluğunun şeker otunun taze ve kuru çiçek verimleri (10.8.2014)

\begin{tabular}{|c|c|c|}
\hline Bitki yoğunluğu & Taze çiçek verimi $\left(\mathbf{k g ~ d a}^{-\mathbf{1}}\right)$ & Kuru çiçek verimi $\left(\mathbf{k g ~ d a} \mathbf{~ d a}^{-\mathbf{1}}\right)$ \\
\hline $\mathbf{3 0 \times 6 0}$ & $93.10 \mathrm{a}$ & $29.94 \mathrm{a}$ \\
\hline $\mathbf{4 5} \times \mathbf{6 0}$ & $45.32 \mathrm{~b}$ & $13.65 \mathrm{~b}$ \\
\hline $\mathbf{6 0} \times \mathbf{6 0}$ & $32.32 \mathrm{~b}$ & $10.17 \mathrm{~b}$ \\
\hline Ortalama & 56.91 & 17.92 \\
\hline EGF $(\% 5)$ & 31.36 & 9.52 \\
\hline
\end{tabular}

Sonuç olarak, şeker otu, yaprakları kullanılan ve kısa günlerde çiçek açan bir bitki olması dolayısıyla, bu çalışma ile ülkemiz koşullarında Akdeniz bölgesinde başarıyla yetişebileceği görülmektedir. Yaz aylarında birçok bölgede yetiştirildiğinde yaprak verimleri alınmakla birlikte, ülkemiz koşullarında kısa günlerin sonbahar kış aylarına rastlaması nedeniyle, çiçek açma ve tohum bağlama da sorunlar yaşanabilmektedir. Ancak Akdeniz bölgesi koşullarında kısa günlerde yeterli sıcaklık isteğini sağlayan bitkide çiçek açma ve tohum bağlamada da sorunlar yaşanmamıştır. En yüksek steviol glikozitleri miktarına çiçeklenme öncesinde sonbaharda kısa günlerde gerçekleşmiş ve herhangibir gübre uygulaması yapılmamış olmasına rağmen elde edilen kuru herba verimleri; Lavini ve ark. (2008), 330$460 \mathrm{~kg} \mathrm{da}^{-1}$, Yang ve ark. (2013), $400 \mathrm{~kg} \mathrm{da}^{-1}$, Lima Filho ve ark. (2004), 350-450 kg da-1,tarafindan belirtilen sınırlar içerisindedir. ulaşıldığ 1 bilinen bitkide, bölgemiz koşullarında dar sıra aralıklarında ve çiçeklenme öncesinde yüksek yaprak verimleri elde edilmiştir.

Sonuçlar göz önüne alındığında, başarılı bir üretim için, şeker otu bitkisinin Akdeniz bölgesi koşullarında don tarihleri dışındaki peryotta, tohumdan direkt ekimden ziyade fideyle üretimi gerekmektedir. Daha ileriki çalışmalarda ticari öneme sahip yaprak verimini artırma amaçlı denemeler yanı sıra fotoperyoda duyarlılığ yönünden üniform özellik gösteren çeşitlerin incelenmesi önerilebilir. 


\section{KAYNAKLAR}

Allam AI, Nassar AM, Besheite SY 2001. Nitrogen fertilizer requirement of Stevia rabaudiana Bertoni under Egyptian condition. Egyptian J. Agric. Res. 79:1005-1018.

Ceunen S,Werbrouck S, Geuns JM 2012. Stimulation of steviol glycoside accumulation in Stevia rebaudiana by red LED light. J Plant Physiol. 169 (7):749-52.

Kafle GG 2011. Some studies on the physiology of Stevia rebaudiana (Bertoni). BSC Agriculture, Institute of Agriculture and Animal Science, Tribhuwon University, Nepal Athesis submitted for the degree of Masters of Applied Science Centre for Plant and Water Science Faculty of Sciences, Engineering and Health CQ University Australia, Rockhampton 31 March 2011.

Kang K and Lee EW 1981. Physio-ecological studies on Stevia (Stevia rebaudiana Bertoni). Korean J. Crops Sci. 26: 69-89.

Global Market, The Demand for Stevia is Bound to Exceed Supply. http://vedratrade.com/images/documents/dossiermkt steviaengvdef.pdf

Lavini A, Riccardi M, Pulvento C, Luca S, Scamosci M, D'andria R 2008. Yield, quality and water consumption of Stevia rebaudiana Bertoni growth under different irrigation regimes in Southern Italy. Italian Journal of Agronomy, v. 2, p. 135-143,

Lima Filho OF, Valois ACC, Lucas ZM 2004. Estévia Sistemas de Produção. Embrapa Agropecuária Oeste. Dourados.

Madan S, Ahmad S, Singh GN, Kohli K, Kumar Y, Singh R, Garg M 2010. Stevia rebaudiana (Bert.), A
Review. Indian Journal of Natural Products and Resources, 1 (3): 267-286.

Metivier J, Viana AM 1979. The effect of long and short day length upon the growth of whole plants and the level of soluble proteins, sugars and stevioside in leaves of Stevia rebaudiana Bert. J. Exp. Bot. 30:1211-1222.

Rajagopal R 2010. Global Stevia Industry Perceptions Report 2009. Knowgenix and Centre for Management Tecnology. Stevia World Americas, 21 $\mathrm{P}$.

Serfaty M, Ibdah M, Fischer R, Chaimovitsh D, Saranga Y, Nativ D 2013. Dynamics of yield components and stevioside production in Stevia rebaudiana grown under different planting times, plant stands and harvest regime. Industrial Crops and Products 50:731-73. soilless culture system. International Journal of Agriculture and Crop Sciences. www.ijagcs.com IJACS.298-302.

Taleie N, Hamidoghli Y, Rabiei B, Hamidoghli S 2012. Effects of plant density and transplanting date on herbage, stevioside, phenol and flavonoid yield of Stevia rebaudiana Bertoni. International Journal of Agriculture and Crop Sciences. 4 (6): 298-302.

Tamura Y, Nakamura S, Fukui H, Tabata, M 1984. Clonal propagation of Stevia rebaudiana Bertoni by stem-tip culure. Plant Cell Rep. 3:183-185.

Tarım ve Köyişleri Bakanlığı, 2010. www.tarim.gov.tr

TUIK. www.tuik.gov.tr

Yang J, Liu X, Shi Y 2013. Effect on different mixer fertilizer on yield, quality and economic benefits in Stevia rebaudiana Bertoni. Advanced Journal of Food Science and Technology, v. 5, p. 588-591. 